\title{
A Rare Case of Sterile Empyema Necessitans with Atypical Acute Presentation
}

\author{
Dr. See Woan Shiang*, Dr. Simon Jerome Vendargon, Dr. Syed Rasul Bin Ghouse Syed Hamid
}

Departement of Cardiothoracic Surgery, Hospital Sultanah Aminah, Johor Baru, Johor, Malaysia

DOI: $\underline{10.36347 / \text { sjmcr.2020.v08i05.021 }}$

| Received: 14.05.2020 | Accepted: 21.05.2020 | Published: 27.05.2020

*Corresponding author: Woan Shiang See

Abstract

Case Report

Empyema necessitans is very rare. It is an extension of infected pleural effusion to the surrounding soft tissue and chest wall region, usually caused by tuberculosis. Sterile empyema necessitans among immunocompetent patients, which is not reported previously, is challenging to physicians in immediate identification and prompt treatments. Here, we present a case of sterile empyema necessitans, and challenges we faced during its management will be discussed.

Keywords: Empyema Necessitans, Thoracic Empyema, Pleuro-cutaneous fistula, Tuberculosis, Thoracotomy, Pleural effusion.

Copyright @ 2020: This is an open-access article distributed under the terms of the Creative Commons Attribution license which permits unrestricted use, distribution, and reproduction in any medium for non-commercial use (NonCommercial, or CC-BY-NC) provided the original author and source are credited.

\section{INTRODUCTION}

Empyema necessitans is a rare disease where an infected pleural effusion extends to the surrounding soft tissue and chest wall region. It is commonly associated with tuberculosis or Gram positive pyogenic infection in immunocompromised patients. Sterile empyema necessitans among immunocompetent patients is not reported previously. Immediate identification can be challenging to physicians and treatments are required as it can pose a significant morbidity and mortality risk to the patient. Here, we present a case of sterile empyema necessitans in a healthy teenager and the challenges we faced.

\section{Case Presentation}

This is a 16 years old young gentleman who presented with 3 days history of painful left anterior chest wall lump, increasing in size but no pus discharge. Further history noted he had productive cough and lethargy for past 2 weeks, but denied any constitutional symptoms, fever or night sweats. He also denied sick contact with patient diagnosed with tuberculosis. No treatment was received prior to this presentation, $\mathrm{He}$ was otherwise healthy with underlying well-controlled bronchial asthma.

On presentation, he was afebrile and hemodynamically stable. Respiratory examination revealed a large abscess over left lower anterior chest wall, measured 10x $10 \mathrm{~cm}$, with reduced breath sound over left lower zone of lung. [Figure 1]

Chest x-ray revealed a massive left pleural effusion.

Blood investigations showed normocytichypochromic anemia $(8.3 \mathrm{~g} / \mathrm{L})$, leucocytosis $(17 \mathrm{x}$

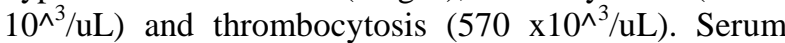
erythrocyte sedimentation rate was high with level of $>120 \mathrm{~mm} / \mathrm{hr}$. C-Reactive Protein was moderately raise (80 $\mathrm{mg} / \mathrm{L})$. Tuberculosis workup and biohazard screenings were negative. Diagnostic needle thoracocentesis revealed a pus collection which was negative for cultures and tuberculosis investigations.

The patient was empirically started on intravenous amoxicillin/clavunic acid $1.2 \mathrm{~g}$ every 12 hourly for pneumonia with parapneumonic effusion.

In order to assess the communication of thoracic and subcutaneous collection, we proceeded with CECT Thorax, which revealed a complex multiloculated left pleural effusion with thickened enhancing nodular pleural lining associated with adjacent lung consolidation. There was presence of adjacent left lower anterior chest wall abscess with communication tract suggestive of pleuro-cutaneous fistula and local extension of the effusion to left subdiaphragmatic region [Figure 2]. 
Considering the large sterile empyema likely in fibrino-purulent stage, open thoracotomy, decortication and debridement of subcutaneous abscess was performed at one week of admission. Intra- operative Pus and tissue culture were negative. Tissue biopsy was negative for malignancy.

He was discharged well one week after surgery.

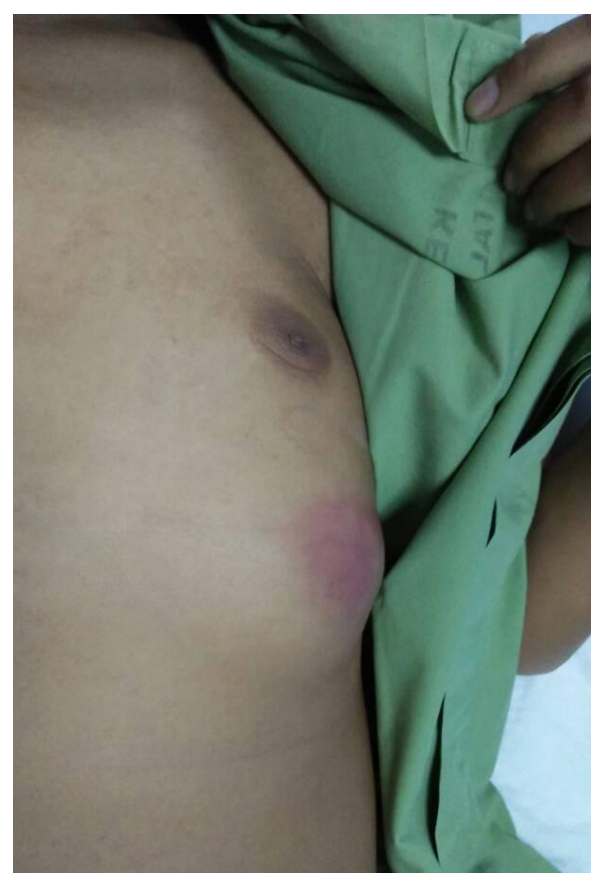

Fig-1: Large left chest wall swelling measured $10 \times 10 \mathrm{~cm}$
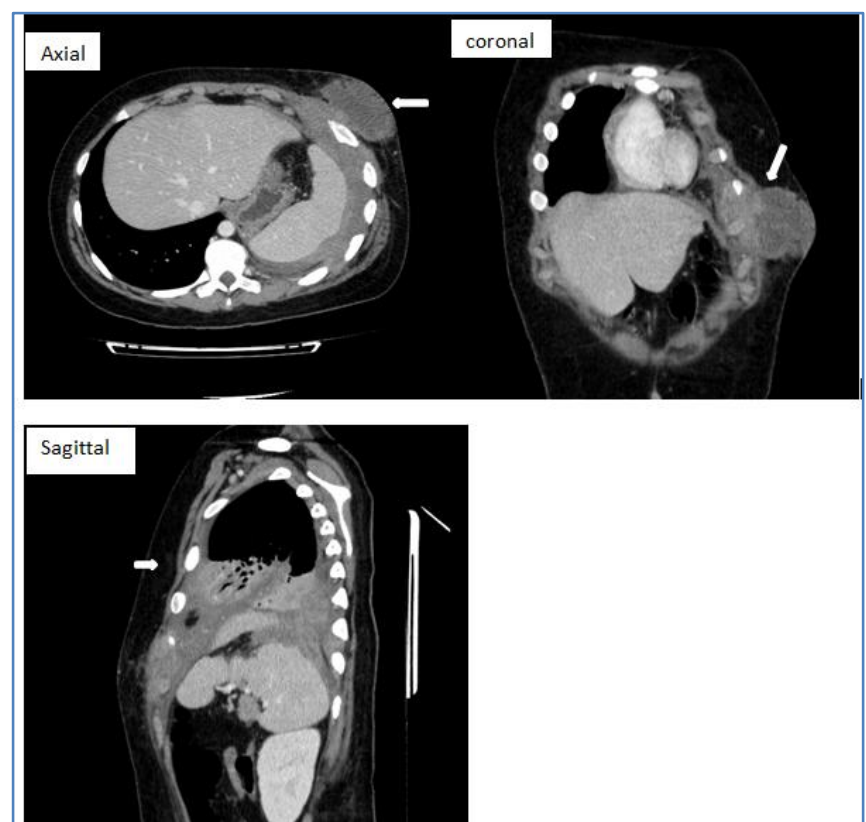

Fig-2: Contrast Enhanced CT Thorax- axial, coronal and sagittal view. It showed large left empyema thoracis fistulate to the left lower chest subcutaneous region and subdiaphragmatic region (white arrows)

\section{DiscUSSION}

Empyema necessitans can be divided into tubercular and non-tubercular cause. In non-tubercular cause, it is commonly caused by gram-positive microorganism. In tubercular empyema necessitans, patients often present with non-specific symptoms due to their suppressed inflammatory process and immunological response [1-3]. On the other hand, empyema necessitans caused by gram-positive microorganisms are commonly seen in paediatric patients who will present with infective symptoms.

In this case, a healthy teenager with nonspecific sysmtoms would mask the suspicion of empyema necessitans which will lead to delay in diagnosis and treatment. The unspecific presentation in an immunocompetent teenager with acute progress is 
therefore, the main concern that we would like to highlight. A non-tubercular empyema necessitans among immunocompetent patients could post a more destructive risk owing to its ongoing inflammatory process to the surrounding tissues. If left untreated, it can further fistulate to surrounding organs like esophagus, diaphragm and retroperitoneal space [4].

Even though rarely, it's typical presentation usually includes an abscess or pus discharge at the anterior chest wall between the mid-clavicular and anterior axillary line, which were consistent with this case.

Normally, empyema necessitans is a chronic complication which requires months for its progression. Here, we would like to highlight the acute disease presentation in our young patient. The disease had shown its aggressiveness which mimics pyogenic infection, despite a negative culture. The patient had not received any treatment prior to admission. We thus decided to start empirical antibiotics based on the local protocol and target age-group [5].

Contrast-enhanced CT thorax scan shouldn't be delayed for empyema necessitans. It shows the communication tract of pleural effusion and surrounding collections. Other features of empyema necessitans include pleural thickening and crowding ribs which are suggestive of chronic empyema. Besides diagnostic purpose, it could delineate the extension of collection which is important for surgical intervention. Without CT Thorax, patient would be managed as chest wall abscess and preceded with incision and drainage. It could result in disastrous outcome.
Management of empyema necessitans involve prompt identification and early treatment including broad spectrum antibiotics, thoracotomy and decortication. In this case, the stage 2 of thoracic empyema was identified and open thoracotomy was done to completely remove the involved tissues to allow re-expansion of lungs. These are the mainstay management to avoid acute progress of respiratory complications.

\section{CONCLUSION}

Early identification and CT scan are essential to identify empyema necessitans with atypical presentation in paediatric patients. Prompt treatment including broad spectrum antibiotics and surgery are the mainstay treatment to avoid respiratory complications.

\section{REFERENCE}

1. Bahamahmoodi F, Davoodi L, Sheikholeslami R, Ahangarkani F. Tuberculous empyema necessitatis in a 40-year-old immunocompetent male. Case Rep Infect Dis. 2016; 4187108.

2. Chaiyasate K, Hramiec J. Images in clinical medicine. Tuberculosis empyema necessitatis. The New England Journal of Medicine. 2005;352(9):e8.

3. Senent C, Betlloch I, Chiner E, Llombart M, Moragón M. Tuberculous empyema necessitatis. A rare cause of cutaneous abscess in the XXI century. Dermatol Online J. 2008;14(3):11.

4. Othman N, Yip CW, Samat NA. Mycoplasma pneumoniae infection complicated by empyema: a rare presentation. Med $\mathrm{J}$ Malaysia. 2005;60(3):389-91.

5. Liam CK, Pendek R, Navaratnam P, Hassan H. Culture-positive thoracic empyema in adults. Med J Malaysia. 1990;45(2):169-76. 